\title{
ADVANCES IN AUTOMATIC TUBERCULOSIS DETECTION IN CHEST X-RAY IMAGES
}

\author{
Wai Yan Nyein Naing, Zaw Z. Htike \\ Department of Mechatronics Engineering \\ Faculty of Engineering, IIUM, Kuala Lumpur, Malaysia
}

\begin{abstract}
Tuberculosis $(T B)$ is very dangerous and rapidly spread disease in the world. In the investigating cases for suspected tuberculosis (TB), chest radiography is not only the key techniques of diagnosis based on the medical imaging but also the diagnostic radiology. So, Computer aided diagnosis (CAD) has been popular and many researchers are interested in this research areas and different approaches have been proposed for the TB detection and lung decease classification. In this paper, the medical background history of TB decease in chest X-rays and a survey of the various approaches in TB detection and classification are presented. The literature in the related methods is surveyed papers in this research area until now 2014.
\end{abstract}

\section{KEYWORDS}

CAD, Tuberculosis, Image processing, Radiographs

\section{INTRODUCTION}

Tuberculosis (TB) is an infection disease over the world population. It is commonly caused by bacteria which is known as Mycobacterium tuberculosis and mostly affected to the lungs of the human beings. TB is spread through the air from everyone or everywhere. By coughing, sneezing, spitting felt in patients, TB bacteria disperses widely into the air. In every year, one third of population of the world has been got Mycobacterium TB bacteria at a rate of one percent of population with new infection.

TB bacteria had caused short lifetime to world population. People over the world infect TB disease about nine million and die over one million for every year. TB symptoms such as cough, getting fever, losing weight, night sweats can easily known whether people have or do not have TB disease. TB is very continuously speeded widely among the different types of people. Therefore, proactive for TB disease is the most suitable to reducing the spread speed. Early detection and taking treatment from the physicians are the best prevention for TB disease. Other methods or techniques for TB detections have been cost in the most of the developing countries. Detection from chest radiography images is the cheapest early detection technique from other detection techniques. Population $80 \%$ of the Asia and African countries has been in TB disease from the tests. Only population 5 to $10 \%$ of the US country has been in TB disease. Handling the TB disease for the developing countries is very expensive, difficult and long time consuming. The World Health Organization (WHO) described the strategy for the TB control to emphasize all the main limitations, factors, etc. This organization produced WHO guidelines, publications and guidelines document for TB disease. 
Signal \& Image Processing : An International Journal (SIPIJ) Vol.5, No.6, December 2014

Large number of patients with TB infections needs to be X-rayed and screen for active TB to ensure a proper treatment of their infections. Taking Standard Chest X-rays (CXRs) is an inexpensive way to screen for the presence of TB. The purpose of screening system is to identify everything that is or could be related to a patient having TB infections. But mass screening of a large population is a time consuming and tedious work, which require considerable effort when done manually. For this reason, Computer-aided diagnostic systems (CAD) used to detect Tuberculosis infections in chest X-rayed. These systems have the potential to lessen the TB detection error risk and also depend on the radiologists [56,57,58,59].

\section{CHEST RADIOGRAPHY \&TUBERCULOSIS SCREENING}

Chest radiography is a popular supporting X-ray image to aid effectively and quickly detection and monitoring respiratory infections such as TB disease and can also be investigated other medical imaging diagnosis. The objective of the present was to check the sensitivity and specificity of symptom and to detect the subject of CXR screening. The three key technical factors of chest radiography are patient's inspiratory effort, degree of penetration or film blackening and adequacy of patient positioning/rotation.

This paper describes the chest radiography in tuberculosis screening. Common employed form of radiography can be acquired from the healthcare clinic and general hospital. By facilitating a dark room and a movable x-ray machine, the radiograph images can be obtained and screening result also.

TB disease screening is suitable in populations where the spread rate of active TB disease very high. The people who are homeless persons, migrant, seasonal workers, the foreign born may have many chances to absorb the TB bacteria. Screening for any disease should begin with a clinical assessment from the laboratory checking. Some of high TB infection are as follows.

- He or she always stay in closely with known or suspected active TB disease

- People infected at risk of infecting HIV

- People who use the illicit drugs injection and high risk users

TB prevention plan always perform over the world is the best production of healthy people.

\section{COMPUTER-AIDED DIAGNOSIS FOR TUBERCULOSIS}

Computer aided detection diagnosis is also known as computer aided diagnosis which is a medical image processing for diagnosing the aid of radiology images. The goal of CAD is not only to get the better result of the diagnostic accuracy but also the consistent radiology image interpretation by using the computer output. CAD output is able to help the radiologists can diagnosis and provide treatment based on the subjective judgment. Normally, there are two types of approaches are applied in computerized schemes for CAD which are finding the location of lesions and quantifying the features of radiography images whether normal or abnormal patterns are included in lungs. Other medical imaging techniques such as X-ray, MRI, ultrasound, etc. produce the information and aid to analyze the detection of tumor in the short time duration.

\section{MEDICAL IMAGING FOR TUBERCULOSIS}

Medical imaging can be performed in the clinical analysis and medical treatment. It is the process, procedure and technique of making optical representations of the interior of a body. Nowadays, medical imaging is not only an essential role in detection but also a diagnosis for 
Signal \& Image Processing : An International Journal (SIPIJ) Vol.5, No.6, December 2014

various diseases. Medical imaging can be seen direct visualization in the human bodies and can be observed very small area of anatomical and biological processes with various parameters. Implementation of image acquisition for example radiography is used in the medical imaging research area such as biomedical engineering, computer science and medical physics. Many of the techniques have been developed for medical imaging and these techniques also can be applied in the scientific and industrial applications. This survey is the medical imaging research field especially for Tuberculosis.

\section{PREPROCESSING}

The main objective of the image preprocessing is not only to improve the quality of image but also to reduce the undesired portion from the background of the images. Most of pre-processing methods applied the intensity value of neighborhood pixel for obtaining the brightness intensity value of the input images. There are dominant reasons for the requirement processes from the image preprocessing phase:

- To meet the requirements of physician for the image quality improvement

- Noise reduction

- Contrast enhancement

- Correction of missing or wrong pixel values

- Optimal preparation of data for postprocessing

- Elimination of acquisition-specific artifacts

In this paper, image segmentation and popular segmentation methods in medical image processing such as graph cut, watershed, Otsu thresholding method, active shape model, active appearance model etc. are presented.

\section{SEGMENTATION}

Among the preprocessing processes, image segmentation is very important to extract good quality features for classification. The key functions of image segmentation are clustering pixels having same intensity value from the whole image regions, separating regions or objects of desired part of the original image, hiding the undesired region or surfaces. Image segmentation are applied in many image preprocessing areas such as recognition of object, object occlusion, estimation of the boundary, editing, or query from image database, image security and image compression.

In general, algorithms for image segmentation are based on two fundamental properties of intensity values which are discontinuity and similarity. Discontinuity property does a partition the image based on the sharp intensity value changes. Similarity property does a partition the image into regions that are like in order to the specified criteria.

In chest radiographs, segmentation process must be done accurately for the medical image analysis task which is especially for computer-aided diagnosis. For example, lung nodules determination is very difficult according to the different measurements of nodules size.

Different kinds of approaches have been discussed [24] in the lung segmentation step. Various methods for lung segmentation are presented which includes pixel classification, rule-based methods, active shapes and other combinations. Three different masks such as the intensity mask, the Log Gabor mask and the lung model mask are used in [6] for lung segmentation. 
Signal \& Image Processing : An International Journal (SIPIJ) Vol.5, No.6, December 2014

\subsection{Graph Cut Based Lung Segmentation}

Lung segmentation is modeled as an optimization problem that takes properties of lung boundaries, regions, and shapes into account $[1,29]$. In general, segmentation in medical images has to cope with poor contrast, acquisition noise due to hardware constraints, and anatomical shape variations. Lung segmentation is no exception in this regard. They therefore incorporate a lung model that represents the average lung shape of selected training masks. These masks are selected according to their shape similarity as follows: firstly all training masks are linearly aligned to a given input CXR. Then, the vertical and horizontal intensity projections of the histogram equalized images are computed. To measure the similarity between projections of the input CXR and the training CXRs, the Bhattacharyya coefficient is used. The average mask computed on a subset of the most similar training masks is used as an approximate lung model for the input CXR. In particular, a subset containing the five most similar training masks is used to compute the lung model. This empirical number produced the best results in the experiments. Increasing the subset size to more than five masks will decrease the lung model accuracy because the shapes of the additional masks will typically differ from the shape of the input x-ray. As training masks, the publicly available JSRT set [30] is used for which ground truth lung masks are available [31]. The pixel intensities of the lung model can be calculated from the possible intensity value of the pixels that is the lung image region.

In a second step, a graph cut approach [32] and model the lung boundary detection with an objective function is employed. To formulate the objective function, three requirements a lung region is defined has to satisfy: a) the lung region should be consistent with typical CXR intensities expected in a lung region, b) neighboring pixels should have consistent labels, and c) the lung region needs to be similar to the lung model are computed.

\subsection{Watershed segmentation}

Watershed segmentation method needs various types of morphological operations and also requires watershed transformation in the segmentation process of the lung regions. Watershed segmentation was primitively used in the partition into image regions [2]. A Watershed segmentation process starts at some regional minima Mi value which locates the lowest points of the area into where the water flows. By measuring an appropriate distance, the area is separated into regions $\Omega$ iwhich has growth from the corresponding minimum Miby adding to $\Omega \mathrm{i}$, repeatedly, unlabelled points on the outer boundary of $\Omega$ i. A point is added to region $\Omega$ iif its distance from the region is smaller than those from other regions. The addition is repeated until no remaining unlabelled points are those of the watershed line. In implementation, to obtain a thin-watershed line, a point is added to the region $\Omega$ ieven when its distance from the region equals those from some other regions. Hence, there is no point belonging to the watershed line. A modification to the Watershed segmentation, the Watersnake approach, is used to adjust the smoothness of regions' boundaries. In [34], a new distance measure is introduced, the gravity measure, and used it in the Watersnake method to segment a lung X-ray image. Due to interference by the ribs, the grey levels of the lung on the left boundary are higher than those on the right. As a consequence, the lung part on the left is constricted, and adjustment is needed to obtain a boundary nearer to the true one.

\subsection{Otsu Thresholding Method}

Thresholding is an object extraction process from its background by determining whether greater or equal to an intensity value T(threshold) for the whole image. Each pixel can be classified as object (pixel) or a background (pixel). In general, thresholding can be categorized into three categories which are global thresholding, local thresholding and dynamic/adaptive thresholding. 
Signal \& Image Processing : An International Journal (SIPIJ) Vol.5, No.6, December 2014

Threshold value of global thresholding is used only one function. Threshold value of local thresholding is used both of a function and local properties of the pixels. The threshold value of dynamic / adaptive thresholding depends on the coordinates of the pixels. The threshold value of Otsu thresholding method uses global thresholding which finds the minimum weighted withinclass variance which means maximizing the between-class variance. Before calculate the threshold value, the following assumptions are applied in otsu method.

- The histogram of the image is bimodal.

- Neither use of spatial coherence nor any other object structure.

- Intensity values are stationary statistics but they can be changed to locally adaptive.

- Intensities are implicitly uniform illumination thus the brightness behavior of the bimodal arises from the object appearance differences only.

\subsection{Active Shape Model \& Active Appearance Model}

Active Shape Model (ASM) is the most popular segmentation method among the other segmentation methods which can be adjusted by using internal parameters. Cootes et al [23] introduced the ASM segmentation method emphasized the free parameters. The ASM scheme includes three elements that are model for the global shape, model for the local multi-resolution appearance, and search algorithm for multi-resolution. Active Appearance Model (AAM) has applied in the medial image segmentation. AAM, modeling for generative or generative model is able to synthesize images of a known object class. Model parameters of AAM can be justified to fit unseen images and hence perform both image segmentation and interpretation process. AAM estimates specifically basis of the training set and AAM uses the same input as ASM that is a set of corresponding points has been indicated in the set of training image dataset.

\subsection{Multi segment active shape model(M-ASM )}

Most of research paper has been discussed the computer-aided detection schemes. Among them lung segmentation is a critical part. Various methods have been proposed for CXRs lungs image segmenting for example which are deformable model based methods, pixel based methods, rule based segmentation methods and hybrid methods. ASM also applied in CXRs lung segmentation. Since conventional ASM cannot accurately be segmented and adjusted variations from the lungs boundaries. In [13], the authors implemented the multi segment ASM (M-ASM) which is adaptive to each multiple segment of the lung boundaries. So, this method is known as multi segment adaption.

\section{FEATURE EXTRACTION}

Feature extraction is the reduction of image feature values and the obtaining of better result of classification results. The feature extraction is a special format for decreasing in dimensionality of the pattern recognition and other image research areas. Features are the distinct shapes or intensity values or feature vector. If the input image is very large to be processed and there contains the redundant data, feature extraction is the essential steps in order to obtain faster speed of classification process. Geometry features and texture features are presented in this paper.The extracted features perform as the basis for classification process. In medical image processing, these features are used to develop diagnostic rules for the cancer nodule detection. 
Signal \& Image Processing : An International Journal (SIPIJ) Vol.5, No.6, December 2014

\subsection{Geometry Features}

Feature such as geometric, photometric, textural can be chosen according to the radiographic manifestation of the abnormalities [19]. The authors proposed a detection method which is called coarse-to-fine feature classification technique. Geometric feature learning is a technique by combining two methods that these are machine learning and computer vision to solve visual tasks. The main objective of geometric feature learning method is finding a set of representative features of geometric shape to represent an object by collecting geometric features from images and is learning them thatmachine learning methods is used efficiently. Geometric feature learning methods not only can be solvedthe recognition problems but also can be predicted the subsequent actions which analyze the sequential input sensory images set.

\subsection{Texture Features}

To imitate radiologist which make visual examination on textural feature of thoracic X-ray images to make diagnosis, [9] exploited textural features calculated by computer to be used as descriptor in classifying images as TB or non-TB.Statistical feature of image histograms is used by calculatingsome featureswhich includes standard deviation (std), mean, kurtosis, skewness and entropy.

\section{Classification}

Image classification is the information extracting from the large testing images[5]. Generally there are two kinds of classification which are described as follow.

- Supervised classification: Supervised classification uses the spectral signatures obtained from training samples to classify an image[38].

- Unsupervised classification: Unsupervised classification finds clusters from the multiband image without the intervention analysis.

\subsection{Fuzzy - ART Neural Networks}

Neural networks have shown as appropriate tools for classification of pulmonary tuberculosis, where the neural networks make a clustering, defining these risks groups for the care of patients [41]. Neural networks have shown to be effective in support roles in the tuberculosis diagnostic, which has been developed based on clinical and histopathological variables to detect the disease.The work [7] presents two models to do a clustering and classify patients of pleural tuberculosis in three risk groups. This clustering uses Fuzzy-Art neural networks to find these groups in the data. Fuzzy-ART neural networks integrate advantages of fuzzy logic operators and the basic characteristics of the implementations ART (Adaptive Resonance Theory), where intersection and union operations used in ART1 implementations are replaced by fuzzy operators [39]. An important advantage of Fuzzy-ART type compare to ART1 networks is the ability of receiving analog and binary data in the inputs. Also presents convergence because their adaptive weights are monotonically non-increasing [40]. A standardized data entry is necessary to define the clustering scenario in the interval $[0,1]$, locating boundaries between zero and one. Different to the ART networks where the clusters are in a hypersphere space, given by the number of variables of the problem to be considered, Fuzzy-ART networks perform the clustering on a hypercube of side one. 
Signal \& Image Processing : An International Journal (SIPIJ) Vol.5, No.6, December 2014

\subsection{Decision Trees}

Decision tree contains nodes and branches. Each node stands for a single decision or test. The start node is called the root node. The tree has branches either right or left and both branches according to the result of a condition. In a binary tree, the decision may be true or false and the test presents a partition orthogonal to one of the coordinates of the decision space.

The radiography images which have included lung nodules varied highly of the distribution of their intensities distinguishing with the normal lung images. One of the popular algorithm called C4.5 is based on decision tree classifier has implemented with the accuracy of 94.9\%. The texture features using tuberculosis index has been proposed in chest radiographs images. The adjunct tool is TI that applied in the radiographers of their daily screening process. The classification of x-ray lung cancer images was implemented in [16]. The proposed method is an inductive decision tree learning algorithm that has high transparency and accuracy and is lower in complexity. The results in [16] showed that the proposed algorithm is accurate, robust, fast, and it outputs a comprehensible structure.

\subsection{Support Vector Machine}

SVM algorithm finds the best hyper plane in the input space. The main purpose of the SVM training is to find the optimized separator function called a classifier. In [1], the authors used a support vector machine (SVM) to detect abnormal CXRs with TB and SVM classifies the computed feature vectors into either normal or abnormal. An SVM in its original form is a supervised non-probabilistic classifier that generates hyperplanes to separate samples from two different classes ina space with possibly infinite dimension $[45,46]$. The unique characteristic of an SVM is that it does so by computing the hyperplane with the largest margin; i.e. the hyperplane with the largest distance to the nearest training data point of any class. Ideally, the feature vectors of abnormal CXRs will have a positive distance to the separating hyperplane, and feature vectors of normal CXRs will have a negative distance. The larger the distance the more confident we are in the class label. This paper therefore used these distances as confidence values to compute the ROC curves.

In [12], the authors proposed the algorithm for identifying and counting the number of tuberculosis bacteria in the development of the microscope imaging. SVM is used in the training and object recognition. The result of development counting is the same as the manual counting result. Therefore, SVM is a good classification method and can also be applied in detecting and counting the number of tuberculosis bacteria. Manikandan et al. [47] have described the SVM is the state-of-the-art classifier in the real world pattern recognition applications.

\subsection{Principal Component Analysis}

PCA is used as the classification method for classifying the x-ray images based on the features extracted by SIFT [5].PCA is a feature based classification technique that is characteristically used for image recognition[42]. The principle features of an image which represents the fundamentals in PCA. PCA identifies features or components that as a whole represent the full object state and termed Principal Components. So, principal components extracted by PCA implicitly present all the features[43]. PCA is a mathematical calculation that applies an orthogonal transformation by convertingthe set of observations of possibly correlated variables into a set of values of linearly uncorrelated variables. 


\section{CONCLUSION}

This paper is surveyed with the analysis of a CAD system for automated analysis of chest x-ray for identification of pulmonary TB. This paper emphasizes to give the steps of TB classification from X-ray images such as preprocessing, feature extraction and classification. Most of researches are going on in this area from several years. Table 1 shows the summary of the review. This paper is based on all these researches and experiments for detecting the possibility of TB in a chest radiograph. This will substantially reduce the effort of Medical officer and radiologist.

Table 1. Summary of Tuberculosis Detection Methods and Accuracy

\begin{tabular}{|c|c|c|c|c|}
\hline Authors & Method & Dataset & Accuracy & Approach \\
\hline Stefan Jaeger [1] & $\begin{array}{l}\text { Binary classifier } \\
\text { and Supportvector } \\
\text { machine (SVM) } \\
\text { are used. }\end{array}$ & $\begin{array}{l}\text { (1)Health } \\
\text { department in the } \\
\text { United States, } \\
\text { (Montgomery } \\
\text { Country Dataset) } \\
\text { (2)The Shenzhen } \\
\text { Dataset) is from } \\
\text { Shenzhen No.3 in } \\
\text { Shenzhen } \\
\text { Guangdong } \\
\text { providence, China }\end{array}$ & $\begin{array}{l}\text { For first set, } \\
\text { classification } \\
\text { accuracy rate } \\
78.3 \% \text { is } \\
\text { obtained } \\
\text { And } 84 \% \text { for } \\
\text { the second } \\
\text { set. }\end{array}$ & $\begin{array}{l}\text { Automated } \\
\text { approach for } \\
\text { Detecting } \\
\text { tuberculosisin } \\
\text { conventional } \\
\text { posteroranterior } \\
\text { chest } \\
\text { radiographs } \\
\text { was presented. }\end{array}$ \\
\hline KIM LE[2] & $\begin{array}{l}\text { Watershed method } \\
\text { also known as the } \\
\text { energy- } \\
\text { minimization } \\
\text { technique. Fuzzy } \\
\text { Logic, Artificial } \\
\text { Neural Network, } \\
\text { Genetic Algorithm } \\
\text { are prospective for } \\
\text { this problem. }\end{array}$ & $\begin{array}{l}\text { No Dataset is } \\
\text { mentioned }\end{array}$ & $\begin{array}{l}\text { No Accuracy } \\
\text { is } \\
\text { mention/just } \\
\text { showing } \\
\text { Detection } \\
\text { Apporach }\end{array}$ & $\begin{array}{l}\text { The design and } \\
\text { implementation } \\
\text { of an } \\
\text { automated X- } \\
\text { ray image was } \\
\text { analyzed which } \\
\text { objective is to } \\
\text { detect early } \\
\text { signs of lung } \\
\text { cancer and TB. }\end{array}$ \\
\hline $\begin{array}{l}\text { Masayu Norman1, } \\
\text { Ahmad } \\
\text { FathilMubashshirAbd } \\
\text { Manaf2, } \\
\text { Noorzalianee } \\
\text { Ghazali1, Zuraihan } \\
\text { Mohamad1 }\end{array}$ & $\begin{array}{l}\text {-the Mean Center } \\
\text { and Standard } \\
\text { Deviational Ellipse } \\
\text { - the Variance } \\
\text { Mean Ratio (VMR) }\end{array}$ & $\begin{array}{l}\text { The data for the } \\
\text { patients was } \\
\text { acquired from } \\
\text { Petaling District of } \\
\text { Health Center, } \\
\text { KelanaJaya.The } \\
\text { data was based on } \\
\text { notification and } \\
\text { Tuberculosis } \\
\text { treatment records } \\
\text { from year } 2005 \\
\text { until year } 2007 \text {. }\end{array}$ & & $\begin{array}{l}\text { The statistical } \\
\text { approaches) } \\
\text { used to } \\
\text { establish the } \\
\text { spatial pattern } \\
\text { and it is } \\
\text { compared with } \\
\text { the graphical } \\
\text { results which } \\
\text { are } \\
\text { presented by } \\
\text { the ArcGIS } \\
\text { software }\end{array}$ \\
\hline $\begin{array}{l}\text { NorlizaMohd. } \\
\text { Noor(Senior Member } \\
\text { IEEE), Omar Mohd. } \\
\text { Rijal, AshariYunus, } \\
\text { Aziah A. } \\
\text { Mahayiddin, Gan } \\
\text { Chew Peng, S. A. R. } \\
\text { Abu-Bakar (Senior } \\
\text { Member, IEEE) }\end{array}$ & $\begin{array}{l}\text {-A vector of } \\
\text { wavelet texture } \\
\text { measures namely, } \\
\text {-maximum column } \\
\text { sum energy, } \\
\text {-modified principal } \\
\text { component } \\
\text { (modPC) method }\end{array}$ & $\begin{array}{l}\text { (1)The archived } \\
\text { data from the } \\
\text { Institute of } \\
\text { Respiratory } \\
\text { Medicine (IPR), } \\
\text { Malaysia. }\end{array}$ & $\begin{array}{l}\text {-when tested } \\
\text { with } \\
\text { validation } \\
\text { sample } \\
\text { achieved } \\
\text { high correct } \\
\text { classification } \\
\text { rate }(94 \%)\end{array}$ & $\begin{array}{l}\text { Texture-based } \\
\text { statistical } \\
\text { discrimination } \\
\text { procedure. }\end{array}$ \\
\hline
\end{tabular}


Signal \& Image Processing : An International Journal (SIPIJ) Vol.5, No.6, December 2014

\begin{tabular}{|c|c|c|c|c|}
\hline $\begin{array}{l}\text { ShafeenaBasheer, } \\
\text { Jayakrishna V, Akas } \\
\text { G Kamal }\end{array}$ & $\begin{array}{l}\text {-(Supervised } \\
\text { classification) } \\
\text {-(Unsupervised } \\
\text { classifica-tion) }\end{array}$ & $\begin{array}{l}\text { (1)The archived } \\
\text { data from National } \\
\text { Institute of } \\
\text { Research in } \\
\text { Tuberculosis(NIRT } \\
\text { ), Chennai,India. } \\
\text {-The trainning set } \\
\text { consists of } 30 \text { PTB } \\
\text { present cases and } \\
30 \text { PTB absent } \\
\text { cases. } \\
\text {-The test set } \\
\text { consists of } 20 \text { PTB } \\
\text { present cases and } \\
20 \text { PTB absent cas- } \\
\text { es }\end{array}$ & $\begin{array}{l}\text {-Images data } \\
\text { set test } \\
\text { results } \\
\text { shows } 50 \% \\
\text { correct } \\
\text { classification. }\end{array}$ & $\begin{array}{l}\text { In the initial } \\
\text { analysis, the } \\
\text { chest } \\
\text { radiograph } \\
\text { provides the } \\
\text { detection of } \\
\text { pulmonary } \\
\text { tuberculosis. }\end{array}$ \\
\hline Stefan Jaeger [1] & $\begin{array}{l}\text { Binary classifier } \\
\text { and Supportvector } \\
\text { machine (SVM) } \\
\text { are used. }\end{array}$ & $\begin{array}{l}\text { (1)Health } \\
\text { department in the } \\
\text { United States, } \\
\text { (Montgomery } \\
\text { Country Dataset) } \\
\text { (2)The Shenzhen } \\
\text { Dataset) is from } \\
\text { Shenzhen No.3 in } \\
\text { Shenzhen } \\
\text { Guangdong } \\
\text { providence, China }\end{array}$ & $\begin{array}{l}\text { For first set, } \\
\text { classification } \\
\text { accuracy rate } \\
78.3 \% \text { is } \\
\text { obtained } \\
\text { And } 84 \% \text { for } \\
\text { the second } \\
\text { set. }\end{array}$ & $\begin{array}{l}\text { Automated } \\
\text { approach for } \\
\text { Detecting } \\
\text { tuberculosisin } \\
\text { conventional } \\
\text { posteroranterior } \\
\text { chest } \\
\text { radiographs } \\
\text { was presented. }\end{array}$ \\
\hline KIM LE[2] & $\begin{array}{l}\text { Watershed method } \\
\text { also known as the } \\
\text { energy- } \\
\text { minimization } \\
\text { technique. Fuzzy } \\
\text { Logic, Artificial } \\
\text { Neural Network, } \\
\text { Genetic Algorithm } \\
\text { are prospective for } \\
\text { this problem. }\end{array}$ & $\begin{array}{l}\text { No Dataset is } \\
\text { mentioned }\end{array}$ & $\begin{array}{l}\text { No Accuracy } \\
\text { is } \\
\text { mention/just } \\
\text { showing } \\
\text { Detection } \\
\text { Apporach }\end{array}$ & $\begin{array}{l}\text { The design and } \\
\text { implementation } \\
\text { of an } \\
\text { automated X- } \\
\text { ray image was } \\
\text { analyzed which } \\
\text { objective is to } \\
\text { detect early } \\
\text { signs of lung } \\
\text { cancer and TB. }\end{array}$ \\
\hline $\begin{array}{l}\text { Masayu Norman1, } \\
\text { Ahmad } \\
\text { FathilMubashshirAbd } \\
\text { Manaf2, } \\
\text { Noorzalianee } \\
\text { Ghazali1, Zuraihan } \\
\text { Mohamad1 }\end{array}$ & $\begin{array}{l}\text {-the Mean Center } \\
\text { and Standard } \\
\text { Deviational Ellipse } \\
\text { - the Variance } \\
\text { Mean Ratio (VMR) }\end{array}$ & $\begin{array}{l}\text { The data for the } \\
\text { patients was } \\
\text { acquired from } \\
\text { Petaling District of } \\
\text { Health Center, } \\
\text { KelanaJaya.The } \\
\text { data was based on } \\
\text { notification and } \\
\text { Tuberculosis } \\
\text { treatment records } \\
\text { from year } 2005 \\
\text { until year } 2007 \text {. }\end{array}$ & & $\begin{array}{l}\text { The statistical } \\
\text { approaches) } \\
\text { used to } \\
\text { establish the } \\
\text { spatial pattern } \\
\text { and it is } \\
\text { compared with } \\
\text { the graphical } \\
\text { results which } \\
\text { are } \\
\text { presented by } \\
\text { the ArcGIS } \\
\text { software }\end{array}$ \\
\hline $\begin{array}{l}\text { NorlizaMohd. } \\
\text { Noor(Senior Member } \\
\text { IEEE), Omar Mohd. } \\
\text { Rijal, AshariYunus, } \\
\text { Aziah A. Mahayiddin, } \\
\text { Gan Chew Peng, S. A. } \\
\text { R. Abu-Bakar (Senior } \\
\text { Member, IEEE) }\end{array}$ & $\begin{array}{l}\text {-A vector of } \\
\text { wavelet texture } \\
\text { measures namely, } \\
\text {-maximum column } \\
\text { sum energy, } \\
\text {-modified principal } \\
\text { component } \\
\text { (modPC) method }\end{array}$ & $\begin{array}{l}\text { (1)The archived } \\
\text { data from the } \\
\text { Institute of } \\
\text { Respiratory } \\
\text { Medicine (IPR), } \\
\text { Malaysia. }\end{array}$ & $\begin{array}{l}\text {-when tested } \\
\text { with } \\
\text { validation } \\
\text { sample } \\
\text { achieved } \\
\text { high correct } \\
\text { classification } \\
\text { rate }(94 \%)\end{array}$ & $\begin{array}{l}\text { Texture-based } \\
\text { statistical } \\
\text { discrimination } \\
\text { procedure. }\end{array}$ \\
\hline
\end{tabular}


Signal \& Image Processing : An International Journal (SIPIJ) Vol.5, No.6, December 2014

\begin{tabular}{|c|c|c|c|c|}
\hline $\begin{array}{l}\text { ShafeenaBasheer, } \\
\text { Jayakrishna V, Akas } \\
\text { G Kamal }\end{array}$ & $\begin{array}{l}\text {-(Supervised } \\
\text { classification) } \\
\text {-(Unsupervised } \\
\text { classifica-tion) }\end{array}$ & $\begin{array}{l}\text { (1)The archived } \\
\text { data from National } \\
\text { Institute of } \\
\text { Research in } \\
\text { Tuberculosis(NIRT } \\
\text { ), Chennai,India. } \\
\text {-The trainning set } \\
\text { consists of } 30 \text { PTB } \\
\text { present cases and } \\
30 \text { PTB absent } \\
\text { cases. } \\
\text {-The test set } \\
\text { consists of } 20 \text { PTB } \\
\text { present cases and } \\
\text { 20 PTB absent cas- } \\
\text { es }\end{array}$ & $\begin{array}{l}\text {-Images data } \\
\text { set test } \\
\text { results } \\
\text { shows } 50 \% \\
\text { correct } \\
\text { classification. }\end{array}$ & $\begin{array}{l}\text { In the initial } \\
\text { analysis, the } \\
\text { chest } \\
\text { radiograph } \\
\text { provides the } \\
\text { detection of } \\
\text { pulmonary } \\
\text { tuberculosis. }\end{array}$ \\
\hline Stefan Jaeger [1] & $\begin{array}{l}\text { Binary classifier } \\
\text { and Supportvector } \\
\text { machine (SVM) } \\
\text { are used. }\end{array}$ & $\begin{array}{l}\text { (1)Health } \\
\text { department in the } \\
\text { United States, } \\
\text { (Montgomery } \\
\text { Country Dataset) } \\
\text { (2)The Shenzhen } \\
\text { Dataset) is from } \\
\text { Shenzhen No.3 in } \\
\text { Shenzhen } \\
\text { Guangdong } \\
\text { providence, China }\end{array}$ & $\begin{array}{l}\text { For first set, } \\
\text { classification } \\
\text { accuracy rate } \\
78.3 \% \text { is } \\
\text { obtained } \\
\text { And } 84 \% \text { for } \\
\text { the second } \\
\text { set. }\end{array}$ & $\begin{array}{l}\text { Automated } \\
\text { approach for } \\
\text { Detecting } \\
\text { tuberculosisin } \\
\text { conventional } \\
\text { posteroranterior } \\
\text { chest } \\
\text { radiographs } \\
\text { was presented. }\end{array}$ \\
\hline KIM LE[2] & $\begin{array}{l}\text { Watershed method } \\
\text { also known as the } \\
\text { energy- } \\
\text { minimization } \\
\text { technique. Fuzzy } \\
\text { Logic, Artificial } \\
\text { Neural Network, } \\
\text { Genetic Algorithm } \\
\text { are prospective for } \\
\text { this problem. }\end{array}$ & $\begin{array}{l}\text { No Dataset is } \\
\text { mentioned }\end{array}$ & $\begin{array}{l}\text { No Accuracy } \\
\text { is } \\
\text { mention/just } \\
\text { showing } \\
\text { Detection } \\
\text { Apporach }\end{array}$ & $\begin{array}{l}\text { The design and } \\
\text { implementation } \\
\text { of an } \\
\text { automated X- } \\
\text { ray image was } \\
\text { analyzed which } \\
\text { objective is to } \\
\text { detect early } \\
\text { signs of lung } \\
\text { cancer and TB. }\end{array}$ \\
\hline $\begin{array}{l}\text { Masayu Norman1, } \\
\text { Ahmad } \\
\text { FathilMubashshirAbd } \\
\text { Manaf2, } \\
\text { Noorzalianee } \\
\text { Ghazali1, Zuraihan } \\
\text { Mohamad1 }\end{array}$ & $\begin{array}{l}\text {-the Mean Center } \\
\text { and Standard } \\
\text { Deviational Ellipse } \\
\text { - the Variance } \\
\text { Mean Ratio (VMR) }\end{array}$ & $\begin{array}{l}\text { The data for the } \\
\text { patients was } \\
\text { acquired from } \\
\text { Petaling District of } \\
\text { Health Center, } \\
\text { KelanaJaya.The } \\
\text { data was based on } \\
\text { notification and } \\
\text { Tuberculosis } \\
\text { treatment records } \\
\text { from year } 2005 \\
\text { until year } 2007 \text {. }\end{array}$ & & $\begin{array}{l}\text { The statistical } \\
\text { approaches) } \\
\text { used to } \\
\text { establish the } \\
\text { spatial pattern } \\
\text { and it is } \\
\text { compared with } \\
\text { the graphical } \\
\text { results which } \\
\text { are } \\
\text { presented by } \\
\text { the ArcGIS } \\
\text { software }\end{array}$ \\
\hline $\begin{array}{l}\text { NorlizaMohd. } \\
\text { Noor(Senior Member } \\
\text { IEEE), Omar Mohd. } \\
\text { Rijal, AshariYunus, } \\
\text { Aziah A. Mahayiddin, } \\
\text { Gan Chew Peng, S. A. } \\
\text { R. Abu-Bakar (Senior } \\
\text { Member, IEEE) }\end{array}$ & $\begin{array}{l}\text {-A vector of } \\
\text { wavelet texture } \\
\text { measures namely, } \\
\text {-maximum column } \\
\text { sum energy, } \\
\text {-modified principal } \\
\text { component } \\
\text { (modPC) method }\end{array}$ & $\begin{array}{l}\text { (1)The archived } \\
\text { data from the } \\
\text { Institute of } \\
\text { Respiratory } \\
\text { Medicine (IPR), } \\
\text { Malaysia. }\end{array}$ & $\begin{array}{l}\text {-when tested } \\
\text { with } \\
\text { validation } \\
\text { sample } \\
\text { achieved } \\
\text { high correct } \\
\text { classification } \\
\text { rate }(94 \%)\end{array}$ & $\begin{array}{l}\text { Texture-based } \\
\text { statistical } \\
\text { discrimination } \\
\text { procedure. }\end{array}$ \\
\hline
\end{tabular}


Signal \& Image Processing : An International Journal (SIPIJ) Vol.5, No.6, December 2014

\begin{tabular}{|c|c|c|c|c|}
\hline $\begin{array}{l}\text { ShafeenaBasheer, } \\
\text { Jayakrishna V, Akas } \\
\text { G Kamal }\end{array}$ & $\begin{array}{l}\text {-(Supervised } \\
\text { classification) } \\
\text {-(Unsupervised } \\
\text { classifica-tion) }\end{array}$ & $\begin{array}{l}\text { (1)The archived } \\
\text { data from National } \\
\text { Institute of } \\
\text { Research in } \\
\text { Tuberculosis(NIRT } \\
\text { ), Chennai,India. } \\
\text {-The trainning set } \\
\text { consists of } 30 \text { PTB } \\
\text { present cases and } \\
30 \text { PTB absent } \\
\text { cases. } \\
\text {-The test set } \\
\text { consists of } 20 \text { PTB } \\
\text { present cases and } \\
20 \text { PTB absent cas- } \\
\text { es }\end{array}$ & $\begin{array}{l}\text {-Images data } \\
\text { set test } \\
\text { results } \\
\text { shows } 50 \% \\
\text { correct } \\
\text { classification. }\end{array}$ & $\begin{array}{l}\text { In the initial } \\
\text { analysis, the } \\
\text { chest } \\
\text { radiograph } \\
\text { provides the } \\
\text { detection of } \\
\text { pulmonary } \\
\text { tuberculosis. }\end{array}$ \\
\hline
\end{tabular}

\section{REFERENCES}

[1] Stefan Jaeger et. al. “Automatic Tuberculosis Screening Using Chest Radiographs”, 2013 IEEE.

[2] KIM LE, "Automated Detection of Early Lung Cancer and Tuberculosis Based on X-Ray Image Analysis", Proceedings of the 6th WSEAS International Conference on Signal, Speech and Image Processing, Lisbon, Portugal, September 22-24, 2006.

[3] Masayu Norman et. al, "Statistical Approach in Determination of Tuberculosis Spatial Pattern", Proceeding of the 2011 IEEE International Conference on Space Science and Communication (IconSpace) 12-13 July 2011, Penang, Malaysia

[4] NorlizaMohd. Noor et. al. "A Statistical Interpretation of the Chest Radiograph for the Detection of Pulmonary Tuberculosis", 2010 IEEE EMBS Conference on Biomedical Engineering \& Sciences (IECBES 2010), Kuala Lumpur, Malaysia, 30th November.

[5] ShafeenaBasheeret. al, "Computer Assisted X-Ray Analysis System for De-tection of Onset of Tuberculosis", International Journal of Scientific \& Engineering Research, Volume 4, Issue 9, September-2013

[6] Stefan Jaeger et. al. "Detecting Tuberculosis in Radiographs Using Combined Lung Masks", 34th Annual International Conference of the IEEE EMBS San Diego, California USA, 28 August - 1 September, 2012.

[7] A. D. Orjuela-Cañón, Fuzzy-ART Neural Networks for Triage in Pleural Tuberculosis, 2013 PAN AMERICAN HEALTH CARE EXCHANGES (PAHCE). CONFERENCE.

[8] RuiShenet. al. "A Hybrid Knowledge-Guided Detection Technique for Screening of Infectious Pulmonary Tuberculosis From Chest Radiographs”, IEEE TRANSACTIONS ON BIOMEDICAL ENGINEERING, VOL. 57, NO. 11, NOVEMBER 2010.

[9] RatnasariNurRohmahLung, "Tuberculosis Identification Based on Statistical Feature of Thoracic Xray", IEEE, 2013.

[10] PATIL S.A. "Texture Analysis of TB X-ray Images Using Image Processing Techniques", Journal of Biomedical and Bioengineering, Volume 3, Issue 1, 2012,

[11] Narayan PENDSE, MD , "Chest Radiography in the field".

[12] KusworoAdi ET. AL "TUBERCULOSIS (TB) IDENTIFICATION IN THE ZIEHL-NEELSEN SPUTUM SAMPLE IN NTSC CHANNEL AND SUPPORT VECTOR MACHINE (SVM) CLASSIFICATION, International Journal of Innovative Research in Science, Engineering and Technology, 2013.

[13] Mrs. J. ShyamalaDev ,"A Study on Improving the Conspicuity of Lung Nodules by use of Virtual Dual-Energy" Radiography," 4th National Conference on Advanced Computing, Applications \& Technologies, May 2014

[14] WHO (2013)Global Tuberculosis Report 2013, World Health Organization

[15] Smear-Negative Multidrug-Resustant Tuberculosis a Significance Hidden Problem for MDR-TB Control: An Analysis of Real World Data”,Journal of Tuberculosis Research, 2014.

[16] Md. Rafiqul Islam et. al. "Medical Image Classification Using an Efficient Data Mining Technique" 
Signal \& Image Processing : An International Journal (SIPIJ) Vol.5, No.6, December 2014

[17] ALI EL-SOLH et. al, "Validity of a Decision Tree for Predicting Active Pulmonary Tuberculosis", American Journal of respiratory and Critical Care Medicine, 1997.

[18] Tan JH, Acharya UR, Tan C, et al. "Computer-assisted diagnosis of tuberculosis: a first order statistical approach to chest radiograph.” J Med Syst 2012;36:2751-9.

[19] Tao Xu, Irene Cheng, Richard Long and MrinalMandal, Novel coarse-to-fine dual scale technique for tuberculosis cavity detection in chest radiographs, $\mathrm{Xu}$ et al. EURASIP Journal on Image and Video Processing 2013, 2013:3

[20] V.Sampath Kumar et. al,Lung Nodules Detection by Computer Aided Diagnosis (CAD) Using Image Processing, International Journal of Advance Research in Computer Science and Management Studies, 2014.

[21] Fan Zhang et. al, "Lung Nodule Classification with Multi-Level Patch-based Context Analysis, IEEE TRANSACTIONS ON BIOMEDICAL ENGINEERING, 2013.

[22] Bram van Ginneken, "Segmentation of anatomical structures in chest radiographs using supervised methods: a comparative study on a public database", Elsevier, 2005.

[23] Cootes, T.F., Taylor, C.J., Cooper, D., Graham, J., 1995, "Active shape models- their training and application", Computer Vision and Image Understanding 61 (1), 38-59.

[24] B. Van Ginneken, B. terHaarRomeny, and M. Viergever, "Computer aided diagnosis in chest radiography: a survey," Medical Imaging, IEEE Transactions on, vol. 20, no. 12, pp. 1228-1241, 2001.

[25] D. Field et al., "Relations between the statistics of natural images and the response properties of cortical cells," J. Opt. Soc. Am. A, vol. 4, no. 12, pp. 2379-2394, 1987.

[26] D. Comaniciu and P. Meer, "Mean shift: A robust approach toward feature space analysis," IEEE Trans. Pattern Anal. Mach. Intell., vol. 24, no. 5, pp. 603-619, May 2002.

[27] G. Dong, N. Ray, and S. Acton, "Intravital leukocyte detection using the gradient inverse coefficient of variation," IEEE Trans.Med. Imag., vol. 24, no. 7, pp. 910-924, Jul. 2005.

[28] C. Di Ruberto and A. Dempster, "Circularity measures based on mathematical morphology," Electron. Lett., vol. 36, no. 20, pp. 1691-1693, Sep. 2000.

[29] S. Candemir, S. Jaeger, K. Palaniappan, S. Antani, and G. Thoma, "Graph-cut based automatic lung boundary detection in chest radiographs," in IEEE Healthcare Technology Conference: Translational Engineering in Health \& Medicine, 2012, pp. 31-34.

[30] J. Shiraishi, S. Katsuragawa, J. Ikezoe, T. Matsumoto, T. Kobayashi, K. Komatsu, M. Matsui, H. Fujita, Y. Kodera, and K. Doi, "Development of a digital image database for chest radiographs with and without a lung nodule," American Journal of Roentgenology, vol. 174, no. 1, pp. 71-74, 2000.

[31] B. Van Ginneken, M. Stegmann, and M. Loog, "Segmentation of anatomical structures in chest radiographs using supervised methods: a comparative study on a public database," Medical Image Analysis, vol. 10, no. 1, pp. 19-40, 2006.

[32] Y. Boykov and G. Funka-Lea, "Graph cuts and efficient n-d image segmentation," Int. J. Computer Vision, vol. 70, pp. 109-131, 2006.

[33] Daniela Stan Raicu, Image Feature Extraction.

[34] Watman, C. and Le, K., "Gravity Segmentation of Human Lungs from X-ray Images for Sickness Classification”, Fourth International Conference on Intelligent Technologies (InTech'03), 2003, pp. 428-434.

[35] Noor NM, Rijal OM, Fah CY. Wavelet a as features for tuberculosis (MTB) using standard x-ray film images.

[36] SUSANTA KUMAR SAHU, Image Segmentation for Text Extraction .

[37] http://en.wikipedia.org/wiki.

[38] Shen R, Cheng I, Basu A. A Hybrid Knowledge Guided Detection Technique for Screening of Infectious Pulmonary Tuberculosis from Chest Radiographs.

[39] Carpenter G. A., Grossberg S., Rosen D., "A neural network realization of Fuzzy-ART", Technical report CAS/CNS-91-021, August 1991.

[40] Faussete L., Fundamentals of Neural networks: architectures, algorithms, and applications. Third Edition, Pearsons Education Publishers.

[41] Baptista de Oiveira e Souza Filho J., Silva Antunes P. H., Seixas J., Maidantchik C., "RedesNeuraisAplicadasaoDiangnóstico da TuberculosePulmonarPaucibacilar" In Portuguese, AutomaticBrazilianCongress, 2010.

[42] Tony Lindeberg, KTH Royal Institute of Technology, Stockholm, Sweden ,’Scale Invariant Feature Transform" 
Signal \& Image Processing : An International Journal (SIPIJ) Vol.5, No.6, December 2014

[43] Feature Based Image Classification by using Principal Component Analysismore by Imran SarwarBajwa.

[44] Imran S. Bajwa1, M. ShahidNaweed, M. Nadim Asif, S. IrfanHy-der,Feature Based Image Classification by using Principal Component Analysis.

[45] V. Vapnik, The nature of statistical learning theory. Springer Verlag, 2000.

[46] B. Sch“olkopf, C. Burges, and A. Smola, Advances in kernel methods: support vector learning. The MIT press, 1999.

[47] K. Suzuki, J. Shiraishi ,H. Abe, H. Mac Mahon, and K. Doi, "False-positive reduction in computeraided diagnostic scheme for detecting nodules in chest radiographs by means of

[48] Noor N M, Rijal OM, Yunus A, et. al A statistical Interpretation of the Chest radiograph for the detection of pulmonary tuberculosis. In Biomedical Engineering and Sciences (IECBES), 2010 IEEE EM BS Conference.

[49] Xu T, Cheng I, Long R, et. al, "Novel Coarse-to-fine dual scale technique for tuberculosis cavity detection in chest radiographs", EURASIP Journal on Image and Video Processing, 2013.

[50] Song YL. "Localization algorithm and implementation for focal of pulmonary tuberculosis chest image". In: Machine Vision and Human-Machine Interface (MVHI), 2010 International Conference on, IEEE 2010:361-4.

[51] Maduskar P, Hogeweg L, Philipsen R, et al. Improved texture analysis for automatic detection of tuberculosis (TB) on chest radiographs with bone suppression images. In: SPIE Medical Imaging, pages: 86700H-86700H. International Society for Optics and Photonics, 2013.

[52] Rijal M, Ebrahimian H, Noor NM. Determining features for discriminating PTB and normal lungs using phase congruency model. In: Biomedical and Health Informatics (BHI), 2012 IEEE-EMBS International Conference on, IEEE 2012:341-4.

[53] Leibstein JM, Nel AL. Detecting tuberculosis in chest radiographs using image processing techniques. University of Johannesburg, 2006.

[54] Koeslag A, de Jager G. Computer aided diagnosis of miliary tuberculosis. Proceedings of the Pattern Recognition Association of South Africa, 2001.

[55] Sarkar S, Chaudhuri S. Automated detection of infiltration and cavitation in digital chest radiographs of chronic pulmonary tuberculosis. In: Engineering in Medicine and Biology Society, 1996. Bridging Disciplines for Biomedicine. Proceedings of the 18th Annual International Conference of the IEEE, IEEE 1997;3:1185-6.

[56] "Implementing the WHO Stop TB Strategy", A Handbook for National TB Control Programmes, 2008.

[57] "WHO Policy on Collaborative TB/HIV activities", Guidelines for national programmes and other stakeholders, Update Version of 2004.

[58] http://en.wikipedia.org/wiki/Mycobacterium_tuberculosis

[59] http://en.wikipedia.org/wiki/Tuberculosis 